\title{
Comunidades terapéuticas: la trasformación invisible
}

\author{
Domingo Comas Arnau
}

Fundación Atenea/GrupoGID.

Enviar correspondencia a:

Domingo Comas.dcomas@ateneagrupogid.org

\section{RESUMEN}

En la actualidad existen 119 Comunidades Terapéuticas en España que están acreditadas y homologadas. Ofertan hasta 3.400 plazas y reciben unos 7.000 ingresos al año (con una estancia media de entre 5 y 6 meses, en programas con una duración media estándar entre 7 y 8 meses), de los cuales 2.900 acaban en un alta terapéutica; en las mismas trabajan alrededor de 1.500 profesionales. Es muy interesante la profunda trasformación que han sufrido en los últimos años para adaptarse a las nuevas políticas sobre drogas y a los cambios en el perfil de los consumidores. Esta adaptación ha dado lugar a una nueva institución, muy diferente a la clásica, muy fuerte y competente, que vuelve a recuperar un cierto protagonismo (aunque ya no mediático sino técnico) en el ámbito de la asistencia a drogas. Son además el subsector de la asistencia a drogas en España más evaluado, con más certificaciones de servicios (ISO y EFOM) y una gran productividad científica.

Han cambiado también los tipos de consumo que son atendidos. En efecto los ingresos cuya droga principal es la cocaína ya representan el 38,7\% de los casos y los de alcohol, con otros problemas como ludopatía y consumo de pastillas y fármacos, el $22,5 \%$. Además un $26,4 \%$ de los internos han recibido un doble diagnóstico muy preciso.

Palabras clave: Comunidades Terapéuticas, demanda asistencial, estudios sociológicos, tratamiento, España.

\section{ABSTRACT}

At the present time, there are 119 Therapeutic Communities in Spain that are accredited and authorised. They provide up to 3,400 places and admit some 7,000 users annually (with an average stay of between 5 and 6 months, in programmes with an average standard duration of between 7 and 8 months), of which 2,900 end by being discharged from therapy. Some 1,500 professionals work in these communities. They have undergone a most interesting and extensive transformation in the last few years, as they adapted themselves to new policies on drugs and the changes in the profile of users. This adaptation has led to a new institution, very different from the classical one, being very strong and competent, and one that is beginning to recover a certain leading role (although technical nowadays, rather than media-related) in the sphere of drug assistance. They are in addition, the most assessed subsector in drug assistance, with most services certifications (ISO and EFQM), and a significant scientific productivity.

The types of users that are treated have also changed. In fact, inpatients whose principal drug is cocaine already represent $38.7 \%$ of the cases, and those on alcohol, with other problems such as gambling and the use of pills and pharmaceuticals, $22.5 \%$ In addition $26.4 \%$ of the inpatients have received a very precise double diagnosis.

Key words: Therapeutic Community, treatment, sociological study, Spain.
$\mathbf{L}$ a realización del Estudio "Comunidades Terapéuticas en España: situación actual y propuesta funcional" recientemente publicado por la Fundación Atenea y la Delegación del Gobierno para el PNsD, muestra como las Comunidades Terapéuticas han realizado, al menos en nuestro país, un tránsito notable. Porque cuando se comenzó a desarrollar la red asistencial eran pocas, aunque producían mucho ruido mediático, muy deficientes en cuanto a su calidad, muy exigentes en sus objetivos y muy dogmáticas en su intervención. En la actualidad son muchas más, en concreto 119 las que están acreditadas y homologadas, ofertan hasta 3.400 plazas, reciben unos 7.000 ingresos al año (con una estancia media entre 5 y 6 meses, en programas con una duración media estándar entre 7 y 8 meses), de los cuales 2.900 acaban en un alta terapéutica y en las mismas trabajan alrededor de 1.500 profesionales.

En general los Equipos de las CCTT homologadas están formados por profesionales bien cualificados y formados, con un predominio claro de psicólogos (que dirigen los centros y actúan como psicoterapeutas), y una fuerte presencia de trabajadores sociales, pedagogos y educadores sociales, sin que falten otras titu- 
laciones. El grupo cuya presencia ha aumentado más rápidamente son los enfermeros, asimismo la tendencia a incorporar médicos y psiquiatras, tras un tiempo en el que se manifestó con intensidad, ha decrecido y aunque algunas CCTT los mantienen, la mayoría recurren a la coordinación con recursos sanitarios y de salud mental externos.

Son además el subsector de la asistencia a drogas en España más evaluado, con más certificaciones de servicios (ISO y EFOM) y una gran productividad científica si atendemos al volumen total de artículos publicados en revistas científicas, entre las cuales Adicciones es un buen ejemplo. A la vez son muchos los profesionales del sector socio-sanitario que imaginan que "las comunidades terapéuticas son cosa del pasado"

¿Cómo es posible que haya producido una trasformación tan radical y casi nadie lo haya percibido? Pues en esencia porque las Comunidades Terapéuticas supieron reaccionar, muy a tiempo y muy bien, ante los malos augurios. Así cuando algunos afirmaron que la ampliación de programas de metadona presagiaba el fin de las Comunidades Terapéuticas, estas invirtieron la tendencia aceptando casos de metadona. Como consecuencia en el año 2005 un 66,3\% de los casos cuya droga principal es la heroína y han sido atendidos en Comunidad Terapéutica utilizan agonistas, un 15\% utilizan antagonistas y sólo un 18,7\% están en un programa libre de drogas.

Además este último grupo solo representa el 2,3\% del total de ingresos en Comunidad Terapéutica (cuando hace 15 años representaba el 100\%), en una gran medida porque las CCTT han sido capaces de enfocar su trabajo hacia los nuevos perfiles, de tal manera que los ingresos con droga principal cocaína ya representan el 38,7\% de los casos y los de alcohol, con otros problemas como ludopatía y consumo de pastillas y fármacos, el 22,5\%. Por si esto fuera poco relevante un $26,4 \%$ de los internos han recibido un doble diagnóstico muy preciso.

Tales cifras muestran la profunda trasformación vivida por estos dispositivos y su capacidad de adaptación, aunque perviven algunas circunstancias adversas. Así un 38,6\% de los casos atendidos en 2005 son judiciales, y muchos de ellos proceden de un sistema (el judicial) que interpreta que las CCTT son más una cárcel alternativa que una alternativa a la cárcel. En el fondo esta situación tiene su propio refrendo en la red asistencial de drogas que sigue, con frecuencia, manejando una imagen tópica de las Comunidades Terapéuticas y sólo deriva hacia las mismas "casos con un pronóstico difícil". Trabajar con protocolos de derivación basado en imaginarios tan poco informados no parece una actitud muy profesional.
También es cierto que esto ocurre en España, un país en el que parece producirse una clara evolución del modelo de Comunidad Terapéutica, con un progresivo abandono de los "principios de Daytop" y su sustitución por el "modelo de Maxwell Jones". Algo que no parece ocurrir, al menos al mismo ritmo, en otros países europeos, aunque, también es cierto, no disponemos de un Estudio sistemático como el mencionado para España, en otros países europeos. El hecho de que esta trasformación se haya producido en España, en todas los antiguos tipos de dispositivos y en todo el territorio, refuerza la idea de un proceso propio, que el Estudio atribuye a diferentes factores.

A la vez la Comunidad Terapéutica española escenifica una de las paradojas de nuestra cultura técnica y administrativa. Es, como ya se ha dicho, uno de los dispositivos evaluados, con criterios científicos, con mayor frecuencia. Pero los resultados de las evaluaciones apenas son tenidos en cuenta. Es más, se sigue insistiendo en que "hay que evaluar". Sin embargo otros dispositivos y programas mucho menos evaluados, gozan, en el imaginario, de mucho más prestigio. Este mensaje de doble vínculo de las administraciones públicas, y que en su día ya describió Carol Weis, (en Wagner y Weiss, Las ciencias sociales y los Estados modernos, México, Fondo de Cultura Económica, 2001), cobra, cuando observamos lo ocurrido en las CCTT españolas, su plena vigencia: Las administraciones y los grupos corporativos están dispuestas a aceptar los resultados de las evaluaciones siempre que se atengan a sus creencias previas e intereses.

Aunque a la vez, y como parte de este doble vínculo, la invisibilidad pública, científica y profesional de las CCTT, se compensa vía presupuestaria. Por este motivo en el año 2005, el subsector ha dispuesto de un presupuesto total estimado en 55 millones de euros, de los cuales 48 millones han sido aportados por las administraciones públicas. Ese dinero se lo reparte un $26 \%$ de centros públicos, un 55\% de centros concertados y un $19 \%$ de centros privados, aunque estos últimos tienen también subvenciones. Como consecuencia un $81 \%$ de las plazas son gratuitas o semigratuitas, y un 19\% son de pago, aunque más de la mitad de las mismas ofrecen una subvención parcial. Conviene también decir que, salvo cuatro CCTT, todas las demás, entre las que no son públicas, pertenecen a ONGs que en general tambien desarrollan otros programas sociales. La proporción entre plazas publicas y privadas es distinta en cada CCAA, pero a la vez todos los Planes Regionales de Drogas ofertan plazas en CCTT.

De hecho la Comunidad Terapéutica vive en España un momento muy singular, no sólo ha asumido con éxito a la nueva coyuntura sino que además ha interiorizado la necesidad del cambio y la adaptación como una de sus características centrales. En un test de 24 
ítems sobre identidad, que han respondido los equipos de las CCTT españolas homologadas, las medias más elevadas las obtienen afirmaciones como "una CCTT debe estar permanentemente observando los cambios en la realidad para adecuarse a los mismos", además el propio test incluía un "índice de consenso" que ofrece las mayores puntuaciones para los ítems relacionado con la adaptación y el cambio. A la vez los ítems que reflejan la pervivencia de la "mística de las CCTT" logran las medias más bajas y las menores puntuaciones en el índice de consenso.

Quizá por este motivo la metodología de la CCTT se está expandiendo en España, como una alternativa de mejora de la calidad, hacia otras áreas, como menores, salud mental o centros para mujeres que sufren maltrato. En resumen la CCTT esta ahí porque nunca desapareció y porque además, en la práctica real, resulta poco prescindible. 
